\title{
Captive husbandry and breeding of the reticulated glass frog, Hyalinobatrachium valerioi (Anura: Centrolenidae)
}

\author{
JAY REDBOND*, HELEN LAMONT, FREYA BOOR \& MIKE TYRRELL
}

The Wildfowl \& Wetland Trust (WWT) Slimbridge Wetland Centre

*Corresponding author e-mail: jay.redbond@wildplanettrust.org.uk

\begin{abstract}
The reticulated glass frog (Hyalinobatrachium valerioi) from Central and South America is a species that has been widely collected from the wild for the pet trade. An ex situ population of this frog was recently established at Slimbridge Wetland Centre, UK, in the hope of learning more about the husbandry and biology of this species. We report on the captive husbandry of adults and the successful breeding and rearing of larvae to metamorphosis. Clutch size was 28 eggs. The eggs hatched at 1518 days after laying and tadpoles reached a total length of $34 \mathrm{~mm}$. The first individuals started metamorphosis 147 days after hatching at water temperatures of $22-28^{\circ} \mathrm{C}$. Hyalinobatrachium valerioi is still being collected from the wild for the international pet trade and to our knowledge this is the first documented breeding of this species in the UK. The husbandry methods described here could be used to breed this and other Hyalinobatrachium species in captivity and so reduce collecting from wild populations.
\end{abstract}

\section{INTRODUCTION}

$\mathrm{T}^{\mathrm{s}}$ he glass frog genus Hyalinobatrachium currently comprises 32 described species (Frost, 2018). They are widely distributed across Central and South America from tropical Mexico to south-eastern Brazil and Argentina with an isolated population in Tobago, West Indies (Ruiz-Carranza \& Lynch, 1991). Hyalinobatrachium valerioi (Dunn, 1931), commonly known as the reticulated glass frog or La Palma glass frog, occurs from central Costa Rica to the Pacific slope of Ecuador; western slope of the western Andes in the Magdalena Valley, Colombia, from sea level to $1500 \mathrm{~m}$ elevation (Dunn, 1931; Taylor, 1951; Taylor, 1958; Starrett \& Savage, 1973; Ruiz-Carranza \& Lynch, 1991; Frank \& Ramus, 1995). Hyalinobatrachium valerioi occurs in lowland moist and wet forest as well as premontane wet forest and rainforest (Savage, 2002). The species is assessed as of Least Concern by the IUCN (Solís et al., 2008).

Hyalinobatrachium valerioi is a nocturnal frog (Guyer \& Donnelly, 2005) and males maintain territories by emitting a call from under leaves during the wet season (Savage, 2002). Male frogs defend their territories aggressively, even fight with rival males, and emit specific calls when another male enters their territory (Savage, 2002). During mating, the female lays a clutch of approximately 35 eggs. The typical oviposition site is the underside of a leaf above running water (Savage, 2002). The female leaves the eggs once they have been fertilised. The male then defends the eggs by attacking any intruding males that come near to the eggs. The male also guard against intruding wasps that have been observed feeding on the eggs and embryos of the frog (McDiarmid, 1978). The male continues to vocalise to attract more females to lay eggs on the same leaf, up to seven different clutches having been seen on one leaf under the protection of a guarding male (Savage, 2002). The male hydrates the eggs by sitting on them and emptying its bladder (Savage, 2002). Although $\mathrm{H}$. valerioi has been kept and bred in captivity the methods used to breed them and rear the tadpole to metamorphosis have not been documented in detail.

\section{METHODS AND RESULTS}

\section{Captive and breeding conditions}

Nine captive-bred H. valerioi were obtained in September 2016 from three private collections in Europe. These comprised two adult males, four adult females and three juveniles (two males, one female). The largest female measured $19 \mathrm{~mm}$ and the largest male was $18 \mathrm{~mm}$. On arrival, one female was obviously gravid as eggs could be seen through the ventral surface, during quarantine she reabsorbed the eggs.

The group was initially housed in a $40 \times 45 \times 38 \mathrm{~cm}$ glass vivarium with a $15 \times 45 \mathrm{~cm}$ mesh ventilation section at the top of the tank with front opening access in our quarantine facility. Despite the fact that this species hides under leaves in the rainforest we provided full spectrum UV lighting as it is likely that the frogs would get some exposure to UV-B radiation naturally through reflection.

UV-B provision was considered particularly important for the healthy development of the juveniles in the group as it is required for vitamin D3 biosynthesis (e.g. Michaels et al., 2015; Tapley et al., 2015) that plays an important role in calcium metabolism, muscle development, organ formation, muscle contraction as well as immune and nervous system functions (Whitaker \& Wright, 2001). We used an Arcadia 7 \% D3 Compact Bulb (Arcadia Products plc, Redhill, UK) which sat directly on the mesh top of the vivarium. UV index was measured weekly with a Solarmeter $6.5 \mathrm{UV}$ index meter (Solartech Inc., Harrison Township, MI); UVI gradients were measured through the mesh and ranged 0-3 UVI at the level 
of the leaves the frogs were under or on top of. While frogs were in quarantine the enclosure was simply furnished with potted plants such as Philodendron hederaceum and Spathiphyllum cochlearispathum, and damp paper towel was used as a substrate, changed weekly. Two small water dishes were provided and these were changed daily and filled with aged tap water, to reduce chlorine content, the tap water at Slimbridge is generally hard with $\mathrm{GH}$ : $6-8{ }^{\circ} \mathrm{d}$ (general hardness). The diet for the frogs consisted of crickets (Gryllus assimilis and Gryllus bimaculatus) and fruit flies (Drosophila melanogaster). Frogs were fed once a week with all food dusted with the dietary supplement Nutrobal (Vetark Ltd., Winchester, UK).

After 6 months, in March 2017, the quarantine period was complete and the frogs were moved into a bespoke glass vivarium $50 \times 65 \times 65 \mathrm{~cm}$ (Figs. 1A and 1B) (Custom aquaria, Rushden, UK). The tank was designed so that seasonal fluctuations from Costa Rica (Table 1) could be mimicked to best reflect the cycle of the animals in the wild for breeding, without having to disturb them and move them to rain chambers. The enclosure design facilitated seasonal flooding using a rain shower head as well as a misting nozzle in case different types of rainfall (drops rather than mists) triggered breeding during the rainy season. The enclosure had a false bottom which allowed water depth to be adjusted according to seasonality. A waterfall was created to circulate the water, flowing down rocks at the back of the tank to the stream from a height of $15 \mathrm{~cm}$, this gave the stream a gentle flow using an EDEN 109 submersible pump (PfG GmbH, Hörstelm Germany) which was situated in the false bottom reservoir. Water temperature ranged from $19-23{ }^{\circ} \mathrm{C}$. The substrate of the stream and banks was gravel; the edges of the artificial stream bank were covered in soil, moss and leaflitter. Plants were provided and planted into the soil around the edge of the water on the banks so that leaves were overhanging the stream; these provided resting sites as well as potential oviposition sites. Only plants from the natural range of $H$. valerioi were provided and these included $S$. cochlearispathum, Philodendron laciniatum, P. hederaceum, $P$. erubescens and Monstera acuminate. We used the same UVB emitting lighting array described earlier, but also introduced a $50 \mathrm{~W}$ basking light (Arcadia Products plc, Redhill, UK) next to the UV light and a GroBeam 1500 ND Natural Daylight LED (Tropical Marine Centre Ltd, Rickmansworth, UK) which was
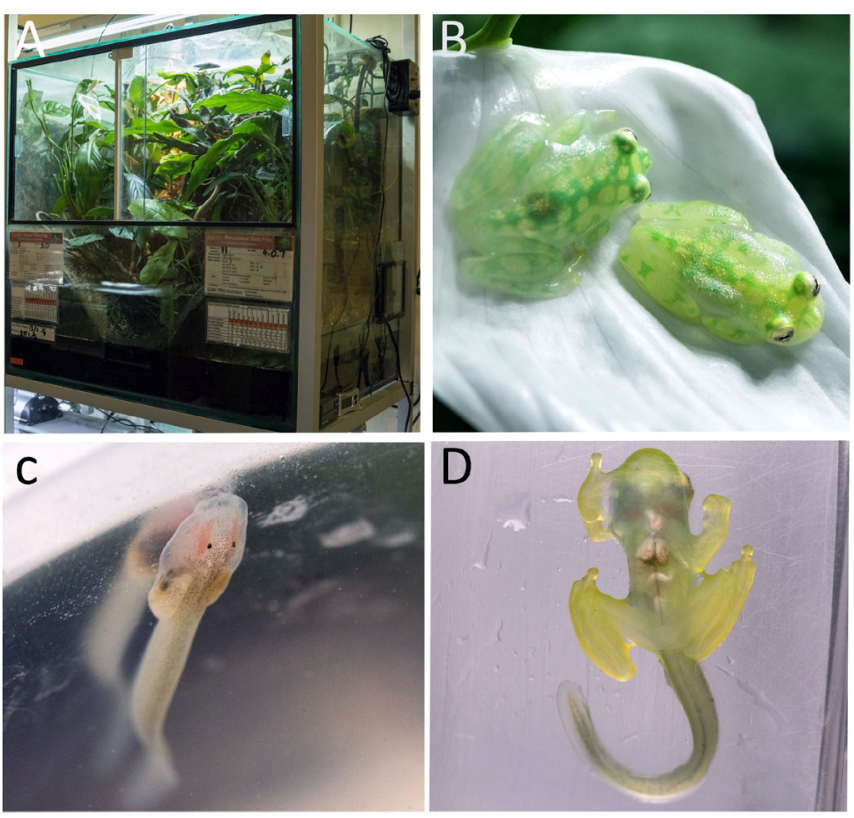

Figure 1. A) Breeding enclosure for H. valerioi; B) Adult $H$. valerioi; C) Tadpole of $H$. valerioi and D) $H$. valerioi near completion of metamorphosis

controlled by an AquaRay SmartControl 8 (Tropical Marine Centre Ltd, Rickmansworth, UK). Photoperiod was adjusted monthly in accordance to climate charts (Weather to travel, 2019) using data from Costa Rica on the season's day length and sunlight hours (Table 1).

Temperature was controlled by HabiStat Digital Temperature Thermostat (HabiStat corporation, Switzerland), Day/Night that was plugged into a $60 \mathrm{~W}, 59 \mathrm{x}$ $28 \mathrm{~cm}$ HabiStat High Power Mat Adhesive. This allowed us to drop temperatures at night and change temperature in accordance with the parameter chart (Table 1). The misting water was provided with locally collected rain water and humidity increased by the use of a misting system through two nozzles in the vivarium that were controlled by an automatic timer, allowing for an adjustable misting period. Misting water was $19-23{ }^{\circ} \mathrm{C}$ with following parameters: $\mathrm{pH}$ 6.8-7, $\mathrm{KH}: 3-6^{\circ} \mathrm{d}$ (carbonate hardness), and $\mathrm{GH}: 8^{\circ} \mathrm{d}$. Although we tried to follow the temperature regime in Table 1 , it was sometimes difficult due to extremes of ambient temperature. Therefore, summer night time temperatures

Table 1. Environmental parameters from Costa Rica that were used as a base line for husbandry parameters in this study (Weather to Travel, 2019)

\begin{tabular}{|c|c|c|c|c|c|c|c|c|c|c|c|c|}
\hline Month & Jan & Feb & Mar & Apr & May & Jun & Jul & Aug & Sept & Oct & Nov & Dec \\
\hline Max day temperature ${ }^{\circ} \mathrm{C}$ & 23 & 24 & 25 & 25 & 25 & 25 & 24 & 24 & 24 & 24 & 24 & 23 \\
\hline Min night temperature ${ }^{\circ} \mathrm{C}$ & 15 & 15 & 16 & 16 & 17 & 17 & 17 & 17 & 17 & 17 & 16 & 16 \\
\hline Hours of day light & 12 & 12 & 12 & 12 & 13 & 13 & 13 & 12 & 12 & 12 & 12 & 12 \\
\hline Hours of sunshine & 7 & 7 & 7 & 7 & 7 & 7 & 6 & 6 & 6 & 6 & 6 & 6 \\
\hline UV index (maximum) & 11 & $11+$ & $11+$ & $11+$ & $11+$ & $11+$ & $11+$ & $11+$ & $11+$ & $11+$ & 11 & 10 \\
\hline Monthly rainfall (mm) & 6 & 7 & 9 & 56 & 261 & 296 & 205 & 282 & 372 & 343 & 155 & 36 \\
\hline Days with some rainfall & 12 & 9 & 8 & 10 & 19 & 24 & 23 & 24 & 24 & 23 & 18 & 16 \\
\hline
\end{tabular}


were often higher than the suggested ambient temperature. The ambient daytime temperature of the enclosure from October- February was $23-24{ }^{\circ} \mathrm{C}$ with night-time drops as low as $17^{\circ} \mathrm{C}$. From March-April day time temperatures were increased to $24-26^{\circ} \mathrm{C}$ and at this point feeding was increased to twice a week to facilitate egg development. The mister was switched off from December - March to simulate the dry season, at this time the enclosure was hand sprayed with an atomiser twice a day mainly for the plants. In March, the mister was switched back on and was set to run daily for the 30 second periods, late morning, early evening and again at night. In early April, the timer was increased to mist for 60 seconds at each period.

\section{Observations on breeding success and tadpoles rearing}

The first clutch of eggs was discovered on 22 April 2018 under a leaf of $P$. erubescens, the clutch contained 28 eggs. As there was a male guarding the eggs, we decided to leave them in situ rather than remove them and risk disturbing the guarding male. During this time, a plastic tub with water collected from the enclosure was placed directly under the eggs so that tadpoles hatching from the nest could be caught in the water below. The first tadpole hatched 15 days after oviposition on 7 May 2018. At this time, the leaf with the eggs on it was moved directly above a tadpole rearing enclosure that had been established in advance with aged, oxygenated tap water. This allowed the tadpoles to drop into the rearing enclosure naturally rather than transferring the tadpoles once they had all hatched. Out of the 28 eggs, one egg was infertile and one tadpole failed to hatch.

A second clutch was found on 31 May 2018, but these eggs were all infertile. The initial tadpole rearing enclosure was $15 \times 20 \times 13 \mathrm{~cm}$ and contained 3 litres of water. A mix of gravel, sand and leaf litter was used as a substrate, simulating the known microhabitats of the tadpoles at the bottom of streams (Rada et al., 2007). This allowed tadpoles to dig into the substrate. A few areas of the enclosure floor were left bare. Tadpoles were provided with oak (Quercus robur) leaves as the leaf litter, which we anticipated would release antioxidants into the water which could potentially aid their development (Szuroczki et al., 2016). An aerator was installed immediately, as the tadpoles would usually live in well oxygenated water. The temperature ranged from 22-28 ${ }^{\circ} \mathrm{C}$, but was usually maintained at the top end of this range $\left(25-28{ }^{\circ} \mathrm{C}\right)$, in the hope of speeding up larval development. The reason for trying this was that it is well documented that some centrolenid frogs have prolonged larval development, which can be in excess of five months (Hoffmann, 2004; Rada et al., 2007) with tadpoles reaching stage 41 in up to 265 days (Hoffmann, 2010). Tadpoles, particularly of stream breeding species, can be very sensitive to water quality and the longer the larval development, the greater the risk of human error and / or technical malfunctions of equipment, which could lead to the death of tadpoles.

Tadpoles were fed on a mix of tropical fish flake and Repashy Superpig (Repashy Ventures Inc, Oceanside, CA), once a day in the morning once the lights were on. On 10 June 2018, tadpoles were moved into a larger tank $25 \times 60 \times 25 \mathrm{~cm}$ with 28 litres of water. All furnishings remained the same but an additional internal filter was installed to process nitrogenous waste. A water change of $25 \%$ was carried out weekly. High ambient temperatures led to excessive evaporation, so that some of the water changes were simply top ups. Water was tested once a month before a water change and nitrogenous waste (nitrite, nitrate and ammonia), which is toxic to aquatic organisms, was measured. Nitrite remained below $0.3 \mathrm{mg} / \mathrm{l}$, nitrate remained below $100 \mathrm{mg} / \mathrm{l}$, and ammonia was never at detectable levels. When the tadpoles were moved, only 15 remained. Water parameters ranged from - $\mathrm{pH}: 6.8-7, \mathrm{KH}$ : 3-6 ${ }^{\circ} \mathrm{d}, \mathrm{GH}: 8^{\circ} \mathrm{d}$ during larval development.

The first tadpoles emerged from the water on 30 September 2018, 147 days after hatching (Fig.1C). They were moved into a $15 \times 20 \times 13 \mathrm{~cm}$ enclosure suitable for metamorphs. This enclosure contained shallow water and plastic plants for metamorphs to climb out onto. Once fully metamorphosed, with resorption of the tail that took 8-10 days (Fig.1D), they were transferred to a tub measuring $15 x$ $20 \times 13 \mathrm{~cm}$. The substrate was gravel covered with moss and live plants ( $P$. erubescens and $M$. acuminata). A small water dish was also provided. Metamorphs began feeding once they had absorbed their tail and were fed on the same diet as the adults.

\section{DISCUSSION}

The rearing of tadpoles to froglets, in this case, suggests that metamorphosis can be faster than previously documented (five months - Hoffmann, 2004; Rada et al., 2007; Hoffmann, 2010) if temperature ranges are kept towards the top end of the tadpoles' thermal tolerance. Rearing tadpoles in this way could be used to influence captive breeding programmes by reducing the cost and time of managing tadpoles which are often more sensitive to suboptimal husbandry than adults.

These observations refer to a single breeding event, consequently further research in captivity of tadpole development times and hatch rate success in the presence of adults is warranted. Parental attendance has led to greater egg survivorship in glass frogs (Lehtinen et al., 2014).

The global trade in amphibians and the lack of associated biosecurity may facilitate the spread of amphibian pathogens (Garner et al., 2009; Martel et al., 2014). A recent proposal to include all centrolenid frogs on appendix II of CITES has been submitted due to the concern that international trade may threaten some species (CITES, 2019). Hyalinobatrachium valerioi is still being collected from the wild for the international pet trade and to our knowledge this is the first documented breeding of this species in the UK. The husbandry methods described here could be used to breed this and other Hyalinobatrachium species in captivity and so reduce collecting from wild populations.

\section{ACKNOWLEDGEMENTS}

We extend our thanks to Benjamin Tapley (Zoological Society of London) for his assistance in the development of this manuscript. We would like to thank Simon Furness and Mick Webber who donated glass frogs to our existing group as well as Jenny Spencer for providing us information on 
her breeding experience of this species. Finally, thanks to John Crooks and Adam Kianchehr for their assistance with the animal care at Slimbridge WWT. Baz Hughes and Marc Boardman who provided comments on an earlier version of this manuscript.

\section{REFERENCES}

CITES (2019). Proposals for amendment of Appendices I and II.https://cites.org/eng/cop/18/prop/index.php Accessed 02 February 2019.

Dunn, E.R. (1931). New frogs from Panama and Costa Rica. Occasional Papers of the Boston Society of Natural History 5: 385-401.

Frank, N., \& Ramus, E. (1995). Complete Guide to Scientific and Common Names of Amphibians and Reptiles of the World. Pottsville, Pennsylvania: N. G. Publishing Inc. 377 pp.

Frost, D. R. (2018). Amphibian Species of the World: an Online Reference (version 6.0). American Museum of Natural History, New York, USA. http://research. amnh.org/herpetology/amphibia/index.html (accessed February 2019)

Garner, T.W.J., Stephen, I., Wombwell, E. \& Fisher, M.C. (2009). The amphibian trade: Bans or best practice. Ecohealth 6 : 148-152.

Guyer, C. \&Donnelly, M. A. (2005). Amphibians and Reptiles of La Selva, Costa Rica and the Caribbean Slope: A Comprehensive Guide. University of California Press, Berkeley. 367 pp.

Hoffmann, H. (2010). The glass frog tadpoles of Costa Rica (Anura: Centrolenidae): A study of morphology. Abhandlungen der Senckenberg Gesellschaft für Naturforschung 567: 46-51.

Hoffmann, H. (2004). Description of the previously unknown tadpole of Hyalinobatrachium pulveratum (Anura: Centrolenidae). Revista de Biologia Tropical 52: 219-228.

Lehtinen, R.M., Green, S.E. \& Pringle, J.L. (2014). Impacts of paternal care and seasonal change on offspring survival: A multiseason experimental study of a Caribbean frog. International Journal of Behavioural Biology Ethology 120: 400-409.

Martel, A., Blooi, M., Adriaensen, C., Van Rooij, P., Beukema, W., Fisher, M.C., Farrer, R.A., Schmidt, B.R., Tobler, U., Goka, K. \& Lips, K.R. (2014). Recent introduction of a chytrid fungus endangers Western Palearctic salamanders. Science 346: 630-631.

McDiarmid, R. W. (1978). Evolution of parental care in frogs. In The Development of Behavior: Comparative and Evolutionary Aspects, pp. 127-147. G. M. Burghardt and M. Bekoff (Eds.). Garland STPM Press, New York, USA.

Michaels, C.J., Antwis, R.E. \& Preziosi, R.F. (2015). Impacts of UVB provision and dietary calcium content on serum vitamin D3, growth rates, skeletal structure and coloration in captive oriental fire-bellied toads (Bombina orientalis). Journal of Animal Physiology and Animal Nutrition 99: 391-403.
Rada, M., Sánchez-Pacheco, S.J. \& Velásquez-Álvarez A.A. (2007). Some considerations on the ex situ management and care of glass frog egg masses and tadpoles (Anura: Centrolenidae). Revista de la Academia Colombiana de Ciencias Exactas, Físicas y Naturales 31: 167-170.

Ruiz-Carranza, P.M. \& Lynch, J.D. (1991). Ranas centrolenidae de Colombia I. Propuesta de una nueva clasificacion generica. Lozania, Bogotá 57: 1-30.

Savage, J.M. (2002). The Amphibians and Reptiles of Costa Rica. University of Chicago Press, Chicago and London. 516 pp.

Solís, F., Ibáñez, R., Chaves, G., Savage, J., Bolaños, F., Kubicki, B., Jaramillo, C., Fuenmayor, Q., Coloma, L.A., Ron, S.R., Cisneros-Heredia, D., Bolívar, W. \& Almendáriz, A. (2008). Hyalinobatrachium valerioi. The IUCN Red List of Threatened Species 2008: e.T55036A11243874. http://dx.doi.org/10.2305/IUCN.UK.2008.RLTS. T55036A11243874.en (accessed January 2019)

Starrett, P. H. Savage, J.M. (1973). The systematic status and distribution of Costa Rican glass-frogs, genus Centrolenella (Family Centrolenidae), with description of a new species. Bulletin of the Southern California Academy of Sciences 72: 57-78.

Szuroczki, D., Koprivnikar, J. \& Baker, L.R. (2016) Dietary antioxidants enhance immunocompetence in larval amphibians. Comparative Biochemistry and Physiology. Part A, Molecular \& Integrative Physiology 201: 182-188.

Tapley, B. (2009). Aspects of captive husbandry of Taylor's bug-eyed frog, Theloderma stellatum (Taylor, 1962). Herpetological Bulletin 108: 31-33.

Tapley, B., Rendle, M., Baines, F.M., Goetz, M., Bradfield, K.S., Rood, D., Lopez, J., Garcia, G. \& Routh, A. (2015). Meeting ultraviolet $B$ radiation requirements of amphibians in captivity: A case study with mountain chicken frogs (Leptodactylus fallax) and general recommendations for pre-release health screening. Zoo Biology 34: 46-52.

Taylor, E.H. (1951). Two new genera and a new family of tropical American frogs. Proceedings of the Biological Society of Washington 64: 33-40.

Taylor, E.H. (1958). Notes on Costa Rican Centrolenidae with descriptions of new forms. University of Kansas Science Bulletin 39: 41-68.

Weather to Travel (2019) https://www.weather2travel.com/ climate-guides/ (accessed February 2019)

Wright, K.M. \& Whitaker, B.R. (2001). Amphibian Medicine and Captive Husbandry. Krieger Publishing Company. 499 $\mathrm{pp}$.

Accepted: 9 October 2019 